\title{
PRODUCTOS CON OPORTUNIDADES DE DESARROLLO EN CHILE: MUCÍlAGO DE ALGARROBO CHILENO (Prosopis
}

chilensis). Daniel Soto y Janina Gysling. Ingenieros Forestales. Instituto Forestal, Chile. dsoto@infor.cl; jgysling@infor.cl. Sede Metropolitana, Área de Economía y Mercado.

\section{RESUMEN}

El Sector Forestal chileno muestra un importante desarrollo basado en las plantaciones forestales y una fuerte industria derivada de estas, pero la producción, que hoy reporta más de 5 mil millones de dólares anuales por retorno de exportaciones, está en una muy alta proporción cimentada en commodities, como pulpa y madera aserrada, entre otros, que involucran una limitada agregación de valor y resultan muy sensibles a los vaivenes económicos internacionales.

Instituto Forestal, en la búsqueda de alternativas de innovación y diversificación productiva en el ámbito forestal, está realizando permanentemente estudios sobre productos con oportunidades de desarrollo en el pais y con este objeto analiza diversos productos madereros y no madereros, sus posibilidades de desarrollo, sus mercados locales y externos. los volúmenes que se transan en el mundo y sus precios.

Recientemente se realizó un estudio sobre carbón vegetal, mucilagos de algarrobo (Prosopis chilensis) y pisos de madera, en el presente trabajo se presenta los resultados obtenidos para mucilagos de algarrobo chileno.

Palabras clave: Mucílagos, Prosopis chilensis, mercado.

\section{SUMMARY}

The Chilean Forestry Sector has an important development based on the planted forests and the strong associated industry, however the production, which currently reports over than 5 thousand million dollars in exports, is composed in a very high proportion by commodities, as pulp, sawn wood and other products, which involves a limited added value and are highly sensitive to changes in the world markets.

The Forest Institute, in searching innovative alternatives and productive diversification in the forest area, is carrying out studies on development opportunities with different products, analyzing wood and non wood forest products, its development possibilities, the domestic and international markets, the volumes sold in the world and the prices.

Recently it was made a study on charcoal, Prosopis mucilage (Prosopis chilensis) and wood floors, results on the second, Prosopis mucilage, are presented in this paper.

Key words: Mucilage, Prosopis chilensis, market. 


\section{INTRODUCCIÓN}

El suministro de proteina vegetal para satisfacer la cadena alimenticia es de vital importancia para los humanos y animales. Actualmente las principales fuentes de proteina vegetal son la soja, glúten o seitán, legumbres, frutos secos, algas marinas y levadura de cerveza y el mayor suministro se obtiene de cereales (trigo, maiz, arroz), con los cuales se preparan las dietas de animales y peces de cultivo y se alimenta gran parte de la población humana. La OMS recomienda en la dieta de las personas una proporción de $25 \%$ de proteina animal y un $75 \%$ de proteina vegetal.

Los aditivos alimentarios juegan un papel de gran importancia en los productos alimenticios en los que se añaden (conservación, textura, aspecto, entre otros) aportando ventajas tanto para la industria como para el consumidor. Se entiende por aditivo alimentario cualquier sustancia que, sin constituir por si misma un alimento, pueda ser añadida intencionadamente a los productos alimenticios en una cantidad minima regulada por reglamento con el fin de modificar sus caracteristicas, las técnicas de elaboración y conservación o para mejorar la adaptación al uso al que son destinados.

La permanencia del aditivo en el alimento o bebida lo diferencia de un coadyuvante tecnológico; su empleo, independientemente de que tenga o no valor nutritivo, lo diferencia de un enriquecedor (vitaminas, minerales, etc.) y su incorporación intencionada al alimento, lo diferencia de un contaminante (pesticidas, etc.).

El empleo de los aditivos alimentarios es, en la actualidad, un hecho indiscutible; gracias a ellos se dispone de alimentos de mayor vida útil, más estables, con una mejor presentación, más variados, etc. A pesar de ello, es motivo de recelos y desconfianza en el consumidor. Muchos asocian el consumo de aditivos con posibles problemas de salud o creen que su uso permite a los fabricantes de alimentos por ejemplo, enmascarar una baja calidad de producto, no estando conscientes de sus eventuales beneficios.

El desarrollo de la quimica y microbiologia de los alimentos, unido a los avances tecnológicos, ha permitido la optimización de los procesos de obtención de aditivos y la aparición de nuevos aditivos con mejores propiedades funcionales y a un menor costo.

Las gomas y mucilagos tienen la capacidad de retener agua y formar suspensiones coloidales y son utilizados en la formulación de muchos alimentos, principalmente por su capacidad texturizante, de viscosidad o espesamiento. También llamados hidrocoloides, en Chile existen exportaciones importantes de estos productos, principalmente elaborados a partir de algas marinas, como la carragenina y el alginato; cabe destacar que Chile es uno de los mayores proveedores mundiales de carragenina. Los hidrocoloides tienen propiedades comunes y en general sus funciones son bastante similares, sin embargo, los efectos que provocan en determinados alimentos son diferentes dependiendo de su tipo, por consiguiente, muchos de ellos deben ser importados, como la goma de algarroba.

El algarrobo chileno, Prosopis chilensis (Mol) Stuntz, es una interesante alternativa que suministra proteina vegetal y que posee el potencial para insertarse en el sector alimentario 
humano y animal. Las iniciativas por industrializar esta especie van desde procesos artesanales, hasta aquellos con procedimientos experimentales para extraer de ellos sustancias útiles, pasando necesariamente por la silvicultura y manejo de masas artificiales y naturales del recurso.

El género Prosopis ha sido investigado, entre otros, en Chile, México y Perú, como materia prima para la obtención de hidrocoloide, el cual se conoce comúnmente como goma mezquite. De acuerdo con la Facultad de Agronomía de la Universidad de Chile, quienes desarrollaron un proyecto para extraer mucilago de Prosopis chilensis, señalaron que esta especie tiene un interesante potencial como productor de goma, pero es necesario profundizar en nuevas investigaciones. Estudios avanzados en México con otras especies de Prosopis, señalan además la necesidad de mejorar técnicas de viverización y manejo silvicola de estas especies de zonas áridas, de manera de asegurar un abastecimiento industrial de acuerdo a los requerimientos del mercado.

La tendencia actual en la industria mundial de alimentos va en la dirección de los productos nutracéuticos o "superalimentos", es decir, aquellos alimentos funcionales y con caracteristicas nutritivas especificas, que son sanos, saludables y ricos. En esta linea destacan los extractos antioxidantes, gomas, espesantes y gelificantes, miel y cera de abejas, y proteinas vegetales hidrolizadas, entre otros. En este sentido, Prosopis chilensis puede ocupar un rol claramente protagónico.

\section{ANTECEDENTES GENERALES DE GOMAS Y MUCILAGOS}

También conocidos como coloides hidrofilicos o hidrocoloides, los mucilagos y gomas forman parte del grupo de los carbohidratos, especificamente de los polisacáridos. Todos los mucilagos y gomas son moléculas complejas compuestas de varios monosacáridos, unos y otros son bastante semejantes en su composición quimica y sólo se diferencian por la forma en que se generan en la planta. Los mucilagos son constituyentes normales de las células, en tanto las gomas se forman por la destrucción de las paredes celulares. Estos carbohidratos son sintetizados por la planta con fines energéticos, como elementos para otorgar elasticidad para el crecimiento, la reproducción y como material de reserva.

Los hidrocoloides son macromoléculas polisacáridos que tienen gran capacidad de retener agua y formar suspensiones coloidales, se usan en la formulación de muchos alimentos principalmente por su capacidad texturizante, de viscosidad o espesamiento. Poseen la ventaja de no impartir aroma ni sabor a los productos en que se añaden, pero inciden en su aceptabilidad ya que mejoran su textura y/o consistencia; su complejidad les impide ser metabolizadas por seres humanos, por lo cual no aportan calorias a la dieta. Los mucilagos y gomas poseen un amplio espectro de acción, como anti-inflamatorias, emolientes (ablandan) y cicatrizantes, actúan como protectoras de las mucosas, son también anti diarreicas (en bajas dosis), laxantes (en altas dosis) y antibióticas.

Estas sustancias son producidas en los frutos, semillas y exudados de los troncos. Con excepción de la gelatina, todos los hidrocoloides son del tipo polisacárido al cual pertenecen los galactomananos (de estructuras poliméricas con unidades de galactosa y manosa), y entre 
ellos están la goma de algarrobo, goma de tara (Caesalpinia spinosa) y de otras especies leguminosas.

Dentro de los diversos materiales que se emplean en elaboración de alimentos, para humanos y animales, los hidrocoloides representan una parte muy importante de los comúnmente llamados aditivos para alimentos. Un mucilago suficientemente purificado es susceptible de ser introducido en alimentos como espesante, estabilizador de suspensiones y espumas (aditivos naturales). Constituyen un grupo de substancias de tipo polimérico con elevado peso molecular, hidrófilos y que, en medio acuoso, se hinchan considerablemente. Cuando se disuelven o dispersan en agua, dan soluciones de alta viscosidad o, según el tipo utilizado, un gel elástico y estable; por eso se usan fundamentalmente como agentes espesantes y de formación de geles.

Existen diversos tipos de hidrocoloides, de los más variados origenes. Los de uso comercial más importantes se presentan en el Cuadro $\mathrm{N}^{\circ} 1$.

\section{Cuadro $\mathrm{N}^{\circ} 1$ \\ PRINCIPALES HIDROCOLOIDES DE USO COMERCIAL}

\begin{tabular}{|c|c|c|c|c|}
\hline Agar & Arabinoxilan & Curdlan & Carragenina & Tragacanto \\
\hline Alginato & Beta Glucan & Gelatina & LBG & Xantano \\
\hline Almidón & Carboximetilcelulosa & Goma Arábiga & Guar & Pectina \\
\hline
\end{tabular}

Algunas de las principales gomas son las siguientes:

\section{Alginato}

El alginato es producido a partir de algas marinas cafés. Existen cerca de 1800 especies de algas cafés, la mayor parte de ellas son marinas y generalmente viven en aguas frias. Unas pocas especies son de uso comercial. En Chile es especialmente importante Macrocystis pyrifera (Figura $\mathrm{N}^{\circ} 1$ ), en tanto que en otros paises destacan Ascophyllum nodosum y Laminaria hyperborea. 


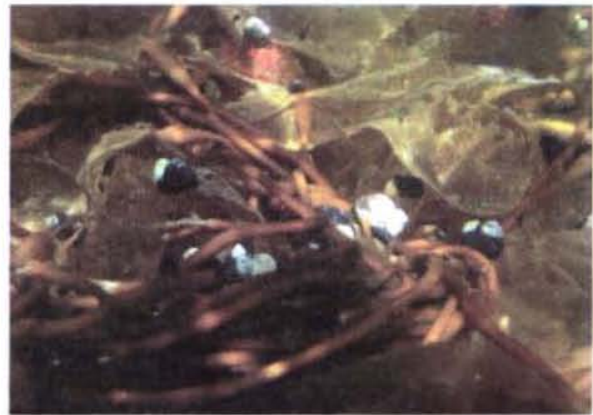

(Fuente: www.alcaebase.org)

Figura $\mathrm{N}^{\circ} 1$

Macrocystis pyrifera COSECHADA EN CHILE

La pared celular de estas algas está compuesta principalmente de celulosa y ácido alginico, que es la materia prima para la elaboración de alginato. El alginato es muy utilizado en dentríficos, helados de crema, carne en conserva, productos lácteos y en la industria de imprenta, entre otros. Dependiendo de la aplicación actúan como estabilizante, espesante o agente gelificador.

\section{Carragenina}

Ingrediente textural con propiedades gelificantes de extremada efectividad, originada de algunas especies de algas rojas. Es utilizada en diversas aplicaciones en la industria alimentaria como espesante, gelificante, agente de suspensión y estabilizante, tanto en sistemas acuosos como en productos lácteos.

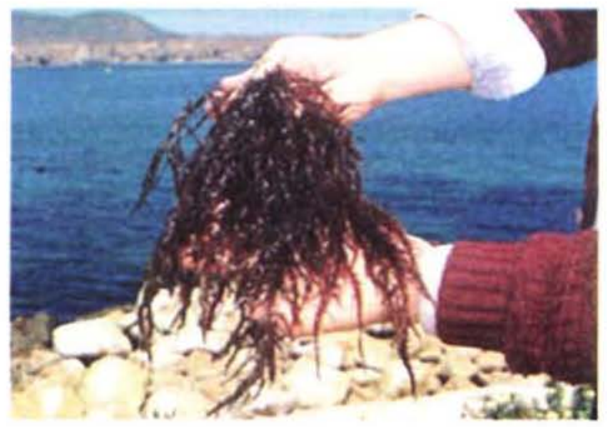

(Fuente: www.alcaebase.org)

Figura $\mathrm{N}^{\circ} 2$

Chondracanthus chamisoi COSECHADA EN LA REGIÓN DE COQUIMBO, CHILE

En el agua, se presenta tipicamente como un hidrocoloide con propiedades espesantes y gelificantes; en la leche, tiene la propiedad de reaccionar con las proteinas y proveer 
funciones estabilizantes. Se obtiene de diversos géneros y especies de algas marinas de la clase Rodophyta. El contenido de carragenina en las algas varia de $30 \%$ a $60 \%$ del peso seco, dependiendo de la especie. Habitualmente, las algas son recolectadas en forma manual por pescadores en zonas inter mareas o por sumersión con ayuda de equipamiento. Despuès de la recolección, las algas son colocadas al sol para secarlas hasta que lleguen a un nivel de humedad ideal para su procesamiento. La carragenina es uno de los principales hidrocoloides que se produce en Chile.

\section{Goma Guar}

La goma Guar se deriva del endospermo molido de la "planta de guar", Cyamopsis tretragonolobus, de la familia de las leguminosas. La planta de guar es anual, de entre 90 a $180 \mathrm{~cm}$ de altura y se cultiva comercialmente en India, Pakistán y Estados Unidos. Se utiliza especialmente como espesante de soluciones acuosas y para controlar la movilidad de materiales dispersados o disueltos. Son conocidas sus excelentes propiedades de sinergia con la goma Xantano.

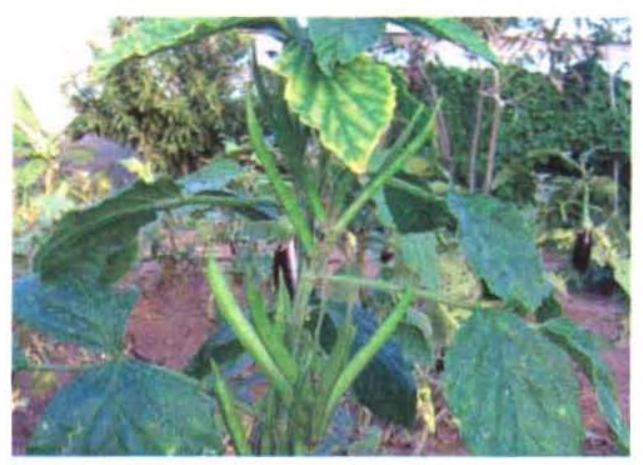

(Fuente: www tropicalfruitlandveg.co.uk

Figura $\mathrm{N}^{\circ} 3$

PLANTA DE GUAR Cyamopsis tretragonolobus

\section{Goma Xantano}

La goma Xantano es un heteropolisacárido exocelular producido por el microorganismo Xantomonas campestris (un patógeno de las coles) mediante un proceso de fermentación. 


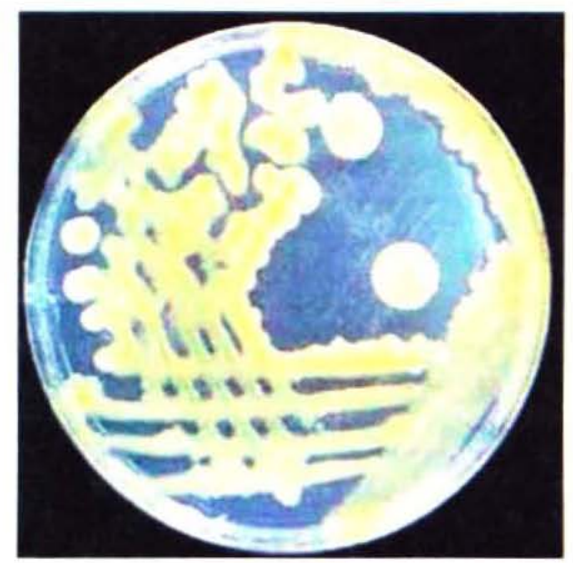

(Fuente: http milksci unizar es)

Figura $\mathrm{N}^{\circ} 4$

\section{PLACA DE AGAR CON CULTIVO DE Kanthomonas campestris}

El micro organismo se cultiva a escala industrial por fermentación aeróbica en un medio formado básicamente por jarabe de glucosa obtenido a partir de la hidrólisis del almidón de maiz. Es soluble tanto en agua fria como en agua caliente, su viscosidad depende poco de la temperatura o del $\mathrm{pH}$, y de la presencia de sales. La goma xantano imparte una viscosidad elevada (en reposo) con pequeñas concentraciones y presenta además un comportamiento pseudo plástico muy marcado. Esta caracteristica la hace ideal para estabilizar y dar viscosidad a productos que deben tener un comportamiento semejante a un gel en reposo (cuando están sobre el alimento) pero fluyen casi libremente cuando se agita el envase para sacarlo de èl (Ejemplo: ketchup).

\section{Goma Garrofin (LBG)}

Esta goma es un hidrocoloide utilizado ampliamente en la industria alimenticia y es también conocida comercialmente por su denominación en inglés Locust Bean Gum (LBG). El LBG se deriva del procesamiento de la semilla de Ceratonia siliqua, una leguminosa arbórea que crece en zonas mediterráneas, conocida comúnmente como garrofero, garrofo, algarroba, Locust Bean o Carob Tree.

El garrofero es un árbol perennifolio de hasta $10 \mathrm{~m}$ de altura, con corteza lisa color gris y hojas lustrosas color verde oscuro. Los frutos son pardos, generalmente derechos y de 10-20 $\mathrm{cm}$ de largo. Las semillas se encuentran empotradas en las vainas espesas y carnosas, ricas en azúcar, normalmente todas del mismo tamaño.

EI LBG es un hidrocoloide perteneciente al grupo de los galactomananos. Entre sus propiedades destacan su acción como espesante en liquidos frios, de la misma forma como la goma xantano; forma geles estables al incorporarse a liquidos en ebullición, trabaja bien en una amplia variedad de $\mathrm{pH}$ y con diversas sales. Durante el congelamiento de ciertos productos. 
LBG retarda la formación de cristales de hielo y otorga excelente textura. La aplicación principal es en preparaciones alimenticias, como salsas, postres, helados y carnes preparadas; en productos lácteos es especialmente utilizado para prevenir la separación de las grasas, sólidos y agua. Actualmente es muy empleado en comida para mascotas. En la industria del papel fue importante hace algunos años, para mejorar las propiedades fisicas, pero hoy su uso está en retroceso.

\section{Goma Mezquite}

Se presenta esta goma por su parentesco con Prosopis chilensis y por el interés de investigaciones recientes. Sin embargo, no tiene actualmente un uso comercial debido a que estả fundamentalmente en etapa de investigación acerca de sus propiedades.

La goma mezquite se obtiene, como se indicó, del género Prosopis, árboles ampliamente distribuidos, principalmente en las zonas áridas y semiáridas de Sudamérica, México y Estados Unidos. Pocas especies de Prosopis han sido estudiadas como potenciales productores de goma. El nombre mezquite ha sido acuñado genéricamente para denominar comercialmente al género Prosopis, no obstante existen nombres comunes propios de cada pais (algarrobo y tamarugo en Chile).

En México, algunas investigaciones han demostrado que el árbol de mezquite, al estar expuesto al ataque de insectos, heridas mecánicas y en condiciones diversas de estrés fisiológico como calor y agua, segrega un exudado o goma de color rojo ámbar y a veces obscuro, a nivel del cambium vascular, que previene la desecación del tejido y evita el ingreso de agentes patógenos. Esta goma ha sido utilizada en la medicina tradicional en poblaciones indigenas, con escaso uso a nivel industrial (López-Franco et. al., 2006).

Del endospermo de la semilla se obtiene un polisacárido de la familia de las galactomananas, a la que pertenecen también las gomas guar (Cyamopsis tetragonolobus), tara (Caesalpinia spinosa) y la LBG (Ceratonia siliqua), utilizadas mayoritariamente como agentes espesantes y estabilizantes de diversas preparaciones alimenticias. Se ha demostrado que la galactomanana del mezquite, al igual que las de uso industrial, tiene capacidad de formar geles sinérgicos con otros polisacáridos, como la goma xantano (López-Franco et. al., 2006).

Pese a que los estudios sobre esta goma son recientes, se ha podido concluir que el polisacárido comparte similitudes en estructura primaria y propiedades emulsionantes con la goma arábiga y que las propiedades funcionales de la goma de mezquite sugieren una potencial aplicación industrial, asi como la importancia del cultivo de esta especie. El principal problema en la actualidad es la disponibilidad de goma de mezquite en cantidades suficientes para asegurar una producción tal que pueda satisfacer la demanda y poder competir en el mercado; sin embargo, técnicas avanzadas de viverización y cultivos in vitro pueden entregar producciones interesantes de goma (López-Franco et. al., 2006). 


\section{ANTECEDENTES DEL MERCADO MUNDIAL DE LOS HIDROCOLOIDES}

El mercado mundial de hidrocoloides se estima en unos US\$19.000 millones (2006), de los cuales el almidón es claramente el que domina el mercado. Excluyendo a este producto y sus derivados, el mercado de los restantes hidrocoloides se estima en unos US\$7.000 millones. A principios de la década del ' 90 el almidón también destacaba sobre el resto de los otros hidrocoloides.

1993

US\$ 10.000 millones

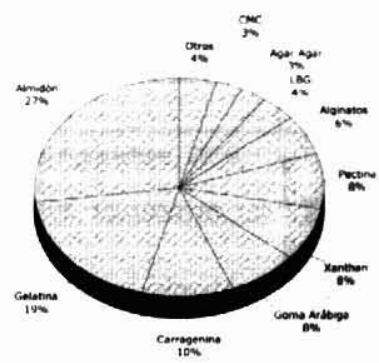

(Fuente: Basurto, 2001)
2006

US\$ 19.000 millones

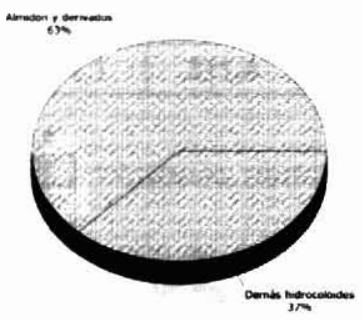

(Fuente: Will et al, 2007)

Figura $\mathrm{N}^{\circ} 5$

MERCADO MUNDIAL DE MUNDIAL DE HIDROCOLOIDES

El almidón y sus derivados tienen menores precios promedio en el mercado que otros hidrocoloides, de tal maneta que frecuentemente el mercado se refiere a estos últimos como hidrocoloides con valor agregado.

Las estimaciones de consumo mundial de hidrocoloides indican un volumen de 16,3 millones de toneladas (2006). Fuera del almidón y sus derivados, Europa constituye el más grande consumidor (43\%), seguido por Norte América (33\%), China ( $7 \%$ ), Japón (5\%) y otros países asiáticos. El resto de los mercados consume comparativamente volúmenes bastante inferiores, que se estiman en $\mathbf{7 7}$ mil toneladas (también excluido el almidón).

El crecimiento que ha mostrado la demanda mundial, en conjunto con los reducidos márgenes que están experimentando muchos negocios, están llevando a los productores de hidrocoloides a focalizar sus estrategias hacia la consolidación en los mercados de hidrocoloides más grandes y más maduros. Hasta hace un par de años el mercado de estos productos se caracterizaba por una baja movilidad en los precios y por la existencia de segmentos con proyecciones de fuerte crecimiento, particularmente la goma xantano y la pectina. En los años 2007 y 2008, el precio de los hidrocoloides se ha caracterizado por alzas importantes.

En los paises desarrollados la demanda de hidrocoloides se caracteriza por ser bastante madura y se estima que hasta el año 2011 el crecimiento de estos productos rondará el 3 a $4 \%$ 
anual. Algunos productos podrian exceder estas tasas, como la goma xantano y la carragenina, mientras que el almidón posiblemente se mantendrá en el piso de este rango de crecimiento. La industria del alimento es la principal aplicación de los hidrocoloides, seguida por la industria del petróleo (como aditivo para fluidos de perforación) y los productos farmacéuticos.

En el año 2007 se constató un importante incremento de los precios internacionales de hidrocoloides, debido a numerosas causas, entre ellas el alza en el precio de las algas y otras materias primas, energia, costos de transporte maritimo y costos de administración del producto. Los productores han hecho importantes esfuerzos en absorber lo más posible los costos asociados de manera de no traspasar el incremento de precios al consumidor, no obstante el escenario actual es de tal magnitud que esto podria revertirse. Para lo que resta de 2008 y para el 2009, se espera un escenario similar de incremento de precios.

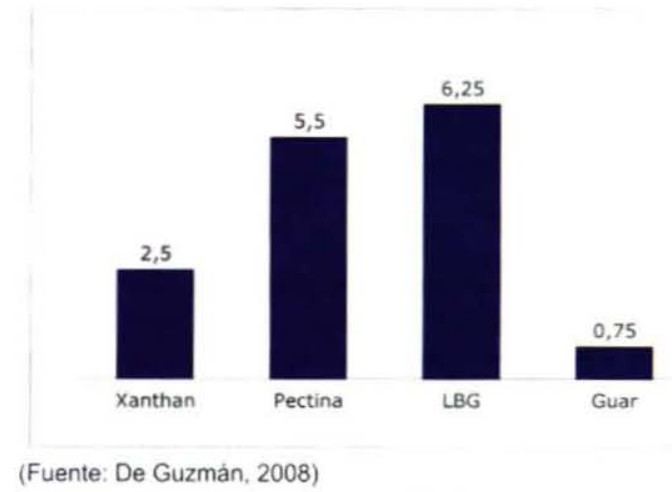

\section{Figura $\mathrm{N}^{\circ} 6$ \\ PRECIO DE ALGUNOS HIDROCOLOIDES EN EL MERCADO INTERNACIONAL (US\$/libra)}

Estados Unidos concentra una importante proporción del consumo de hidrocoloides, donde el almidón y sus derivados son los principales productos utilizados, mientras que otros de mayor valor agregado, como el alginato, goma guar, LBG y la goma arábiga le siguen a distancia. El crecimiento de unos y otros se debe fundamentalmente a la habilidad que poseen de interactuar con los variados ingredientes que se incorporan a los alimentos y en mejorar sus propiedades texturales mediante gelificación, espesamiento y emulsión. Por lo tanto, el crecimiento de estas gomas está intimamente ligado, entre otros, al crecimiento en el consumo de alimentos preparados. 


\section{Cuadro $\mathrm{N}^{\circ} 2$ \\ IMPORTACIONES DE ALGUNOS HIDROCOLOIDES EN EEUU (US\$ millones)}

\begin{tabular}{|l|c|c|c|c|c|}
\hline Producto (código HSUS) & $\mathbf{2 0 0 3}$ & $\mathbf{2 0 0 4}$ & $\mathbf{2 0 0 5}$ & $\mathbf{2 0 0 6}$ & $\mathbf{2 0 0 7}$ \\
\hline Goma Guar (1302320020) & 45,2 & 55,7 & 85,7 & 134,9 & 116,1 \\
\hline Carraghenina (1302390010) & 51,0 & 55,1 & 62,3 & 62,0 & 65,6 \\
\hline Pectina (1302200000) & 53,6 & 49,2 & 49,6 & 52,2 & 54,2 \\
\hline Goma Arábiga (1301200000) & 24,3 & 32,2 & 55,7 & 51,0 & 38,2 \\
\hline Locust Bean Gum (1302320040) & 16,5 & 22,3 & 35,8 & 36,8 & 32,2 \\
\hline Agar-Agar (1302310000) & 19.0 & 19,3 & 19,3 & 23,6 & 28,8 \\
\hline Otros * & 4,6 & 7,3 & 3,1 & 4,1 & 34,5 \\
\hline TOTAL & $\mathbf{2 1 4 , 1}$ & $\mathbf{2 4 1 , 1}$ & $\mathbf{3 1 1 , 4}$ & $\mathbf{3 6 4 , 5}$ & $\mathbf{3 6 9 , 7}$ \\
\hline
\end{tabular}

Fuente: US Department of Agriculture, 2008

Nota: No incluye almidón.

$\because 1301904000,1301909105,1301909110,1301909120,1301909130,1301909140,1301909190,1302390090$.

El mercado para el almidón utilizado en alimentación es de unos US\$ 270 millones solo en Estados Unidos. Los segmentos claves para la industria del almidón y sus derivados son las comidas preparadas, postres, preparaciones de carnes y comidas que requieren recubrimientos especiales. El mayor productor estadounidense es National Starch, seguido por las compañias Staley y Cargill. Estas dos últimas han redireccionado sus estrategias de negocios para focalizarse en otros nichos, como ingresar al mercado de la goma xantano, la cual es menos madura que el almidón, pero entregaria márgenes mucho más atractivos.

Por su parte, Europa se constituye como el mercado mundial más grande de hidrocoloides, pero es seguido cercanamente por el mercado norteamericano. Pese a ello, existen algunos tipos de productos con mayor presencia en uno y otro mercado, como la goma xantano, que es mucho más importante en Estados Unidos, y la pectina, que lo es en Europa. 


\section{Cuadro $\mathrm{N}^{\circ} 3$ \\ IMPORTACIONES DE ALGUNOS HIDROCOLOIDES EN EUROPA (US\$ millones)}

\begin{tabular}{|l|c|c|c|c|c|}
\hline Producto (código TARIC) & $\mathbf{2 0 0 3}$ & $\mathbf{2 0 0 4}$ & $\mathbf{2 0 0 5}$ & $\mathbf{2 0 0 6}$ & $\mathbf{2 0 0 7}$ \\
\hline Pectina (13022010, 13022090) & 156,8 & 172,2 & 177,4 & 184,3 & 215,7 \\
\hline Goma Arábiga (13012000) & 68,7 & 119,5 & 213,5 & 136,0 & 147,5 \\
\hline Guar (13023290) & 88,4 & 99,4 & 120,4 & 129,1 & 137,1 \\
\hline Locust Bean Gum (13023210) & 62,5 & 87,4 & 120,3 & 106,4 & 107,4 \\
\hline Agar-Agar (13023100) & 26,1 & 29,7 & 34,4 & 46,5 & 50,1 \\
\hline Otros * & 293,0 & 339,8 & 351,6 & 375,8 & 458,0 \\
\hline TOTAL & $\mathbf{6 9 5 , 4}$ & $\mathbf{8 4 7 , 9}$ & $\mathbf{1 . 0 1 7 , 6}$ & $\mathbf{9 7 8 , 0}$ & $\mathbf{1 . 1 1 5 , 8}$ \\
\hline
\end{tabular}

Fuente: Eurostat, 2008.

Nota: No incluye almidón.

: 13019000, 13019010, 13019090, 13023900.

El bajo crecimiento poblacional, conjuntamente con un moderado crecimiento económico, hará que en los próximos cuatro o cinco años la tasa de crecimiento anual de hidrocoloides en el oeste de Europa sea sólo de un 1,5\%, mientras que en el mercado del este y centro de Europa, comparativamente más reducido que el anterior, el crecimiento será más acelerado, cercano a un $5 \%$.

En la mayoria de las aplicaciones de hidrocoloides se proyectan moderados crecimientos, sin embargo, una excepción la constituyen las aplicaciones realizadas en los campos de petróleo, donde la goma guar y sus derivados han experimentado un excepcional crecimiento. Históricamente la competencia entre hidrocoloides ha sido importante, especialmente con polimeros sintéticos o semi sintéticos; en este sentido, muchas formulaciones que incluyen hidrocoloides son altamente sustituibles, por ejemplo, como consecuencia del incremento en el precio. En Asia el mayor consumidor es Japón, con cerca del $54 \%$ de la demanda regional de hidrocoloides, principalmente de origen importado, con excepción del agar, alginato, carragenina y gelatina. China, con el $44 \%$, es el segundo mayor consumidor.

De acuerdo con ProChile (2008) el mercado global de los aditivos e ingredientes, donde se incluyen los hidrocoloides, es bastante dificil de cuantificar, principalmente por tres razones:

- Los productores de ingredientes son empresas generalmente muy discretas. Actúan en un mercado de extrema competencia que, a veces, puede ser de relativa facilidad para cuantificar y de compradores bien definidos. Las empresas de dicho rubro están permanentemente en confrontación con un mercado muy activo, en el cual los cambios de control accionario y otras reestructuraciones financieras acontecen a ritmo acelerado. Los grandes compran y los pequeños son comprados. En este contexto, gran parte de las empresas evitan revelar datos.

- Las caracteristicas propias de la estructura de los grandes grupos industriales 
involucrados en la producción de aditivos alimenticios. Empresas gigantes como Archer Daniels Midland, Cargill, Eridania Béghin-Say, Tate \& Lyle y muchas otras, procesan y comercializan tanto commodities como ingredientes y productos alimenticios listos para la venta al por menor. En este caso se hace dificil analizar los informes anuales de los grandes grupos y descubrir números especificos del negocio de ingredientes. Otros grandes conglomerados como CHR Hansen, están involucrados en la producción y comercialización de muchos tipos de aditivos diferentes, que no permiten cálculos de liderazgo de mercado y otros relevantes datos de marketing o de demanda especifica.

La concentración de la industria a nivel mundial. Con fusiones y adquisiciones que acontecen casi semanalmente en un mundo globalizado, las grandes empresas del rubro están especializándose aún más, eliminando de sus portafolios los negocios que no pertenecen a su core business. Otras deciden separar claramente alguna gran unidad de negocios, en una operación independiente, creando una nueva empresa. Dichas operaciones de compra y venta generan nuevas entidades con volümenes de venta diferentes, dificultando de esa forma el monitoreo de la información.

\section{PERSPECTIVAS DE DESARROLLO DEL MUCILAGO DE PROSOPIS CHILENSIS EN CHILE}

\section{Comercio Exterior de Gomas y Mucilagos Vegetales}

La información estadistica de las diversas gomas y mucilagos vegetales que se exportan e importan se clasifica principalmente en las partidas del Capitulo 13 del Sistema Armonizado, con excepción del almidón y algunos derivados de la celulosa. 


\section{Cuadro $\mathrm{N}^{\circ} 4$ \\ CÓDIGOS DEL SISTEMA ARMONIZADO CHILENO \\ PARA EL COMERCIO EXTERIOR DE ALGUNOS HIDROCOLOIDES}

\begin{tabular}{|c|c|c|}
\hline Partida & Código & Glosa \\
\hline \multirow[t]{3}{*}{13.01} & & $\begin{array}{l}\text { Goma laca; gomas, resinas, gomorresinas y oleorresinas naturales (por } \\
\text { ejemplo, bálsamos). }\end{array}$ \\
\hline & 1301.2000 & Goma arábiga \\
\hline & 1301.9000 & Los demás \\
\hline \multirow[t]{8}{*}{13.02} & & $\begin{array}{l}\text { Jugos y extractos vegetales; materias pécticas, pectinatos y pectatos; } \\
\text { agar-agar y demás mucilagos y espesativos derivados de los vegetales, } \\
\text { incluso modificados. }\end{array}$ \\
\hline & 1302.2000 & Materias pécticas, pectinatos y pectatos \\
\hline & & Mucílagos y espesativos derivados de los vegetales, incluso modificados \\
\hline & 1302.3100 & Agar-agar \\
\hline & 1302.3200 & $\begin{array}{l}\text { Mucilagos y espesativos derivados de la algarroba o de su semilla o de las } \\
\text { semillas de guar, incluso modificados. }\end{array}$ \\
\hline & 1302.39 & Los demás \\
\hline & 1302.3910 & Carragenina \\
\hline & 1302.3990 & Los demás \\
\hline
\end{tabular}

(Fuente: Servicio Nacional de Aduanas, 2006).

Chile tiene una importante exportación de hidrocoloides, principalmente aquellos derivados de vegetales marinos. El principal y que reporta los mayores montos exportados es el agar-agar, un polisacárido derivado de algunas algas rojas, fundamentalmente de los géneros Gelidium, Euchema y Gracilaria. Gelidium que están entre los más importantes a nivel mundial, pero en Chile la exportación de agar-agar se origina casi enteramente de Gracilaria, muy abundante en las costas del pais. Chile exporta agar-agar a cerca de 40 paises y es el mayor productor mundial en la actualidad; de las 7.500 toneladas anuales que se movilizan en el mercado mundial de agar-agar, unas 2.500 se originan en el pais.

La carragenina, también originada de algas rojas, es el segundo hidrocoloide con mayor monto exportado. Destacan en esta exportación la empresa nacional Gelymar S.A. y Danisco S.A., esta última de capitales daneses. Otros polisacáridos tienen menor importancia exportadora.

Por el lado de las importaciones, destacan la carragenina y la goma de guar. Si bien este último producto corresponde a una glosa arancelaria (1302.3200) que incluye dos especies (guar y garrofero), de acuerdo con las bases de datos de comercio exterior de INFOR, la importación es mayoritariamente de goma guar. 


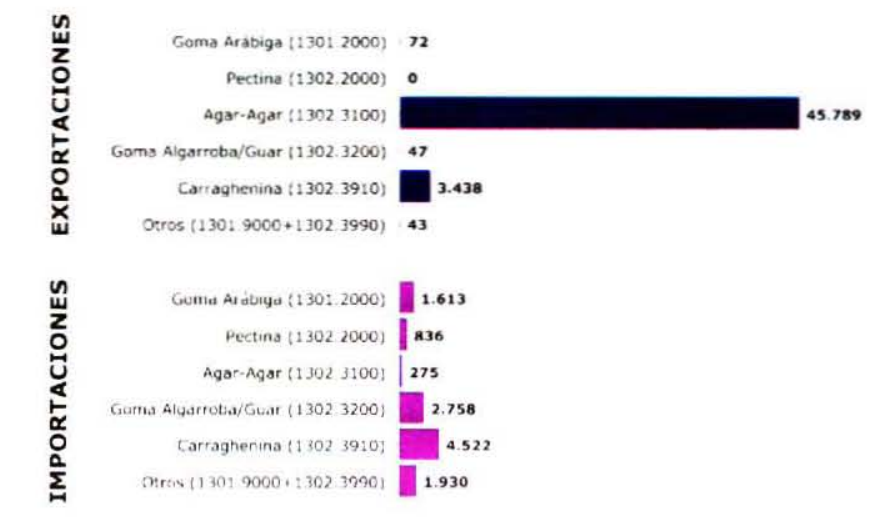

(Fuente: Servicio Nacional de Aduana, 2008. INFOR. 2008)

Figura $\mathrm{N}^{\circ} 7$

COMERCIO EXTERIOR DE HIDROCOLOIDES EN CHILE, 2007 (US\$ miles)

En Chile han existido pocas experiencias en el desarrollo investigativo del mucilago de Prosopis chilensis, básicamente centradas en los trabajos de la Facultad de Agronomia de la Universidad de Chile a principios de la presente dècada. En el año 2001, CONICYT financió el proyecto "Hidrocoloides de especies de zonas áridas: extracción, caracterización y aplicaciones" ejecutado por dicha Facultad, el cual tenia como objetivo general poner a punto métodos para extraer los hidrocoloides de dos especies de zonas áridas: algarrobo chileno y nopal (tuna). y lograr una caracterización de éstos. En particular para el algarrobo, se estudiaron métodos secos (molienda) y húmedos, para la separación y posterior extracción de la goma.

Con el desarrollo del proyecto, se entregaron las bases para la obtención y mayor conocimiento de los hidrocoloides, lo que permitirá a futuro explorar la posibilidad de un desarrollo a escala industrial. A modo de ejemplo, en un estudio realizado por Ramirez (2006) en el marco del proyecto mencionado, se consideró la preparación de un tipo de postre alimenticio. budines, en los cuales se analizaron dos alternativas a la tradicional goma xantano con la que son elaborados comúnmente; goma de algarrobo chileno y goma de tara. La incorporación de estas dos gomas como reemplazo del xantano presentó sinergias y otorgó buena consistencia a los budines preparados. De acuerdo con el estudio, la calidad de los budines no se alteró significativamente hasta un máximo de $75 \%$ de reemplazo por goma de algarrobo y goma de tara, siendo a la vez muy similar a la formulación testigo, elaborada enteramente con goma xantano.

De acuerdo con la Facultad, la utilización del algarrobo permitirá un mejor uso de los suelos de las zonas áridas, mayores posibilidades para los habitantes de dichas zonas y la posibilidad de sustituir gomas de amplio uso procedentes del exterior, como la goma guar. Cabe señalar además, que este proyecto puede representar un beneficio no sólo para Chile sino también para otros paises que se encuentran en las zonas áridas del mundo y que deben batallar contra la erosión y la pobreza, entre otras desventajas de dichas zonas. 


\section{Normativa sobre los Alimentos}

En Chile, el Reglamento Sanitario de los Alimentos (Decreto 977/96 del Ministerio de Salud) es el cuerpo que regula y establece las condiciones sanitarias a que deberá ceñirse la producción, importación, elaboración, envase, almacenamiento, distribución y venta de alimentos para uso humano, con el objeto de proteger la salud y nutrición de la población y garantizar el suministro de productos sanos e inocuos.

El reglamento considera como aditivo alimentario a cualquier sustancia que no se consume normalmente como alimento por si mismo ni se usa como ingrediente típico del alimento, tenga o no valor nutritivo, cuya adición intencional al alimento para un determinado fin (organoléptico, de almacenamiento, etc.) llegue a ser un complemento del alimento o que afecte sus caracteristicas.

Para ser un aditivo autorizado por este reglamento, el carácter inocuo de éstos debe ser evaluado toxicológicamente, considerando especialmente los efectos carcinogénicos, mutagénicos y teratogénicos, en diferentes especies de animales como asimismo en estudios bioquímicos y metabólicos. Todos los aditivos deberán cumplir las normas de identidad, de pureza y de evaluación de su toxicidad de acuerdo a las indicaciones del Codex Alimentarius de $\mathrm{FAO/OMS}$. Los aditivos deberán declararse obligatoriamente en la rotulación, con su nombre especifico según el Codex Alimentarius, y en orden decreciente de proporciones.

El Articulo 49 del Decreto mencionado detalla todas las sustancias espesantes, hidrocoloides o estabilizantes que están permitidas en los alimentos comercializados en Chile:

Agar

Alginato de amonio, de calcio y de sodio

Alginato de propilenglicol

Almidones modificados

Almidones pregelatinizados

Carrageninas o carragenos

Carragenatos

Celulosa microcristalina

Carboximetilcelulosa

Croscaramelosa sódica

Etil-celulosa

Hidroxipropilcelulosa

Hidroxipropilmetilcelulosa

Metilcelulosa
Metiletilcelulosa

Furcelerano o agar danés

Gelatina

Goma arábiga

Goma garrofin o de semilla de algarrobo

Goma gelan

Goma guar

Goma karaya

Goma tara

Goma tragacanto

Goma xanthana

Pectinas 
Cabe señalar que en la lista anterior no están presentes las gomas que se han elaborado a partir de Prosopis spp., debido a que éstas aún se encuentran en proceso investigativo y de validación alimenticia, fundamentalmente con algunas especies de Prosopis en Perú y México.

\section{Antecedentes de la Especie Prosopis chilensis}

Prosopis chilensis crece en Chile, Argentina, Perú y Bolivia. En Chile se desarrolla en zonas desérticas y de clima mediterráneo perárido, árido y semiárido, ocupando suelos de buen drenaje. Se desarrolla en áreas montañosas en piedemontes o planos inclinados de depósito en faldeos de cerros y en terrazas aluviales antiguas, en sectores con acuiferos superficiales y subterráneos.

En poblaciones naturales hay individuos arbustivos, sub arbóreos y arbóreos muy grandes, y con gran variabilidad en la presencia y magnitud de las espinas, y en el tamaño y forma de los frutos. Es un árbol fijador de nitrógeno. Su importancia y usos son variados; posee rápido crecimiento, es adecuado para forestación de zonas áridas y semiáridas, tiene un alto valor forrajero de frutos y hojas y también se le utiliza para fines dendroenergéticos. La madera es apta para construcciones y artesanias, además de su valor ornamental como árbol de sombra por su copa amplia y elegante follaje.

Según INFOR (2007), la superficie plantada con algarrobo en Chile al año 2005 era de 5.140 ha, aproximadamente un $0,2 \%$ de la superficie total nacional de plantaciones forestales, estando más concentrada en la Región de Tarapacá (3.246 ha).

Los frutos de Prosopis chilensis tienen 7 a $11 \%$ de proteinas, $30 \%$ de mucilagos, $26 \%$ de fibra y 1,6 a $2 \%$ de rutina y quercitina (flavonoides), teniendo muy buena digestibilidad y bajo tenor graso, razón por la cual son utilizables en la alimentación humana y animal

Considerando sólo las semillas (sin vainas), cambian las proporciones anteriores, puesto que éstas contienen un $32,0 \%$ de proteina, $2,5 \%$ de aminoácidos esenciales (metionina y cisteina) $3,0 \%$ de lipidos, $8,4 \%$ de fibra y $42,8 \%$ de hidratos de carbono. Por ejemplo, los frutos o vainas del algarrobo blanco son ricos en hidratos de carbono y proteinas de valor nutricional, y proveen hierro y calcio, presentando un bajo contenido graso y buena digestibilidad. Como su contenido de hidratos de carbono es menor que el de la harina de trigo, su consumo es aconsejable para los diabéticos. Además, permite la elaboración de alimentos para celiacos, dado que la harina no contiene glúten (Vásquez et al, 1988).

\section{Procesamiento del Fruto para Extracción de Mucílagos}

Los procesos industriales para la obtención de productos del fruto del algarrobo se basan en la molienda y separación de éstos en fracciones. Todos los procesos probados señalan que los frutos deben estar muy secos, con contenidos de humedad cercanos al $5 \%$ debido a que se debe manejar el alto contenido de azúcares en los frutos. Los porcentajes de humedad superior causan problemas en las máquinas de molienda. El proceso descrito para algarrobo tiene un esquema como el que se describe en la Figura $\mathrm{N}^{\circ} 8$. 


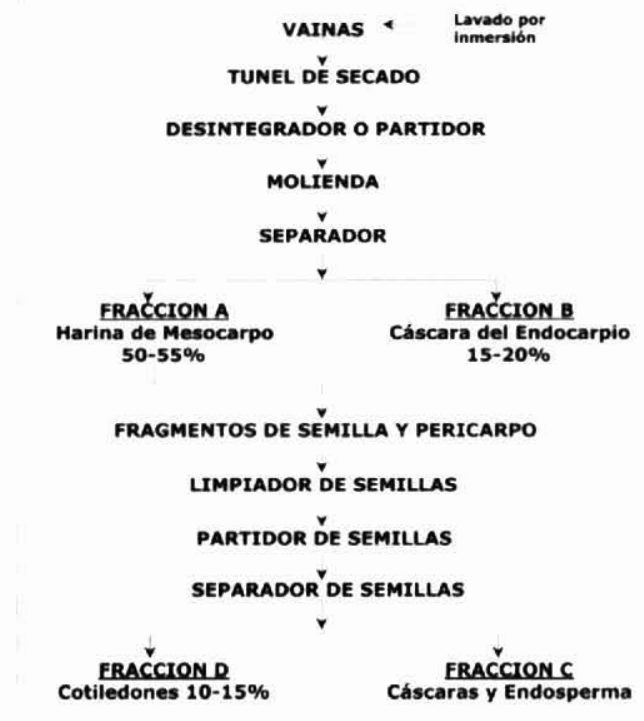

(Fuente: Vásquez et al, 1988).

\section{Figura $N^{\circ} 8$ \\ ESQUEMA GENERAL DEL PROCESAMIENTO INDUSTRIAL DE VAINAS DE ALGARROBO}

Fracción A: Corresponde a la harina de algarrobo. Es la fracción más importante de todo el conjunto de productos y representa cerca del $60 \%$ del fruto; se compone principalmente de azúcares (sucrosa, glucosa, fructosa), por ello, se le utiliza como sustituto de la harina de trigo y cereales. El gusto especial de la harina de algarrobo lo potencia como un componente interesante en el área de los endulzantes o bien como parte de los productos de reposteria. También, por su contenido de alcoholes, seria útil para energía.

Fracción B: Representa el 20 a $25 \%$ de los frutos. El análisis químico no revela que esta fracción sea interesante desde el punto de vista de los alimentos y menos para el consumo humano. Es muy rudo y fibroso, por lo que requiere mucha molienda y eventualmente tratamiento de calor para su uso. No tiene valor nutricional dado que la mayor parte de él son fibras.

Fracción C: Representa un $40 \%$ de cubierta de semilla y un $60 \%$ de endosperma que contiene una goma del tipo galactomanano. La cubierta de semillas no tiene valor nutricional. El galactomanano es el producto económicamente interesante de esta fracción, pues se puede utilizar como elemento para la farmacopea, alimentación humana y de animales. 
Fracción D: Esta fracción contiene básicamente los cotiledones de las semillas y constituyen una fuente interesante de proteinas y grasas (Vásquez et al., 1988).

Prosopis chilensis, como todas las especies del género, posee un potencial interesante para la producción de mucilagos galactomananos ya que se caracterizan por poseer entre sus componentes, polisacáridos desarrollados generalmente porque la planta crece en marcadas condiciones de estrés. El endosperma de las semillas de Prosopis contiene galactomananos que pueden ser separados mediante un proceso acuoso, produciendo gomas con un $85-95 \%$ de pureza.

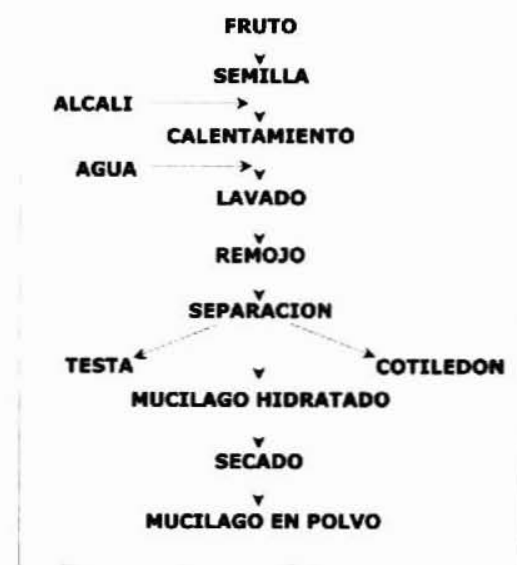

(Fuente: Vásquez et al, 1988)

\section{Figura $\mathrm{N}^{\circ} 9$ \\ ESQUEMA GENERAL DEL PROCESAMIENTO \\ INDUSTRIAL DE VAINAS DE ALGARROBO \\ PARA OBTENCIÓN DE MUCÍLAGO}

Vásquez et al. (1988), presentan la siguiente tabla con la composición quimica proximal de la semilla de Algarrobo. 


\section{Cuadro $\mathrm{N}^{\circ} 5$ \\ COMPOSICIÓN QUÍMICA PROXIMAL DE SEMILLA, VAINA SIN SEMILLA Y MUCÍLAGO DE ALGARROBO \\ $(\mathrm{g} / 100 \mathrm{~g})$}

\begin{tabular}{|c|c|c|c|}
\hline & Semilla & Vaina sin Semilla & Mucilago \\
\hline Humedad & 14,8 & 12,8 & 8,0 \\
\hline Cenizas & 2,9 & 2,8 & 1,9 \\
\hline Proteina (NX6,2,5) & 26,8 & 6,5 & 6,9 \\
\hline Extracto etéreo & 3,2 & 1,6 & 0,2 \\
\hline Fibra cruda & 7,2 & 18,5 & 1,3 \\
\hline Extracto no nitrogenado* & 45,0 & 58,0 & 81,7 \\
\hline
\end{tabular}

- Por diferencia

\section{CONCLUSIONES}

- Las gomas y mucilagos de origen vegetal constituyen un importante grupo entre los aditivos alimentarios, los cuales son sustancias que no son un alimento en si mismas, sino que añaden a éstos cualidades de conservación, textura, aspecto, viscosidad y otros, de gran interés tanto para la industria como para el consumidor.

- También llamados hidrocoloides, las gomas y mucilagos se encuentran en una gran variedad de plantas, en sus frutos, semillas y como exudación de sus troncos. Excepto la gelatina, todos los hidrocoloides son del tipo polisacáridos, grupo que contiene a los galactomananos, en el cual se encuentra la goma de algarrobo, la goma de tara y la de otras leguminosas.

- El almidón y sus derivados son, por mucho, los principales hidrocoloides de uso comercial, con un consumo masivo y precios inferiores al resto de los hidrocoloides. El mercado mundial se estima en US\$19 mil millones, con una participación del almidón y sus derivados superior al $63 \%$.

- Hay una gran variedad de hidrocoloides distintos del almidón y sus derivados, todos de uso comercial. Entre estos se pueden mencionar: agar, alginato, carragenina, xantano, pectina, goma arábiga, goma guar, goma garrofin y goma mezquite. En volumen, se estima que el mercado mundial de estos hidrocoloides alcanza a 272 mil toneladas, donde Europa es el mayor consumidor con una participación de $43 \%$, seguido por Norteamérica con $33 \%$, China con $7 \%$ y Japón con $5 \%$.

- A nivel mundial, el mercado de hidrocoloides no muestra una tendencia de crecimiento rápido, estimándose que para el año 2011 éste alcanzará una tasa media anual entre $3-4 \%$. 
- Chile es el mayor productor mundial de agar-agar, con una participación de un tercio de las 7.500 toneladas que se movilizan anualmente en el mercado. Pero tambièn Chile importa otros tipos de hidrocoloides para su consumo, entre los que se encuentra la goma guar.

- $\quad$ La producción y uso de goma a partir de Proposis chilensis, algarrobo, tiene buenas perspectivas, particularmente porque esta especie crece muy bien en zonas áridas y semiáridas, donde el establecimiento de otra vegetación es muy dificil o de costo muy alto. Sin embargo, es necesario investigar varios aspectos de la silvicultura, manejo e industrialización de la especie, para llegar a determinar su potencial comercial en la producción de mucilago.

\section{REFERENCIAS}

Basurto, L., 2001. Estudio de Mercado sobre Gomas o Hidrocoloides: Resinas y Látex. En: http://www.geocities.com/lebr7/goma2.htm

CONICYT, 2001. Proyecto "Hidrocoloides de Especies de Zonas Áridas: Extracciön, caracterización y aplicaciones. Resumen en http://ri.conicyt.cl/575/article-14131.html

De Guzmán, D., 2008. Hidrocolloids Price under Preasure.En

http://www.icis.com/Articles/2008/01/28/9095601/Hydrocolloids-price-under-pressure.html

EUROSTAT, 2008. Servicio de Información Estadistica de la Unión Europea. En http://epp. eurostat.ec.europa.eu/portal/page/portal/external_trade/introduction

INFOR, 2007. Estadisticas Forestales Chilenas 2006. Boletin Estadistico 117. Instituto Forestal, Ministerio de Agricultura. Chile. 163 p.

INFOR, 2008. Base de Datos de Exportaciones e Importaciones. Instituto Forestal. Unidad de Estadisticas. Sede Metropolitana. Santiago, Chile.

López-Franco et. al., 2006. http://www.scielo.org.ve/scielo.php?script=sci_arttext\&pid=S0378$18442006000300007 \&$ lng=es\&nrm=iso\&tlng=es

ProChile, 2008. El Mercado Mundial de Ingredientes y Aditivos. En http://www.prochile.cl/ newsletters/america_sur/brasil_aditivos_1mercado.php

Ramírez, M. 2006. Elaboración de un Postre Lácteo con incorporación de Gomas de Algarrobo (Prosopis chilensis (Mol) Stuntz) y Tara (Caesalpinia spinosa). Tesis Ingeniero Agrónomo. Escuela de Agronomia, Facultad de Ciencias Agronómicas. Universidad de Chile. 41 p. En: http://www.cybertesis.cl/tesis/uchile/2006/ramirez_m/html/index-frames.html

Servicio Nacional de Aduanas, 2006. Arancel Aduanero de la República de Chile. Decreto $N^{\circ} 997$ (DO 16 diciembre 2006) Modifica el Arancel Aduanero Nacional. Servicio Nacional de 
Aduanas, Ministerio de Hacienda. Chile.

Servicio Nacional de Aduana, 2008. Base de datos ESTACOMEX on line. En http://200.72.160.89/estacomex/asp/index.asp.

US Department of Agriculture, 2008. Foreing Agricultural Service's US Trade Internet System. En <http://www.fas.usda.gov/ffpd/fpd.html>. Consulta: Junio 2008.

Vásquez, M., Carbonell, E. y Costell, E., 1988. Comportamiento Reológico de Soluciones Acuosas de la Goma de Algarrobo (Prosopis chilensis (Mol.) Stuntz). Comparación con el de las gomas guar y garrofin. Rev. Agroquimica y Tecnologia de Alimentos 12(12): 251-260.

Will, R; Loechner, U; and Yokose, K., 2007. Hidrocolloids (Abstracts). En http://www. sriconsulting.com/CEH/Public/Reports/582.7000/> 